\title{
Axonal Targeting of Trk Receptors via Transcytosis Regulates Sensitivity to Neurotrophin Responses
}

\author{
Maria Ascaño, Alissa Richmond, Philip Borden, and Rejji Kuruvilla \\ Department of Biology, Johns Hopkins University, Baltimore, Maryland 21218
}

Axonal targeting of trophic receptors is critical for neuronal responses to extracellular developmental cues, yet the underlying trafficking mechanisms remain unclear. Here, we report that tropomyosin-related kinase (Trk) receptors for target-derived neurotrophins are anterogradely trafficked to axons via transcytosis in sympathetic neurons. Using compartmentalized cultures, we show that mature receptors on neuronal soma surfaces are endocytosed and remobilized via Rab11-positive recycling endosomes into axons. Inhibition of dynamin-dependent endocytosis disrupted anterograde transport and localization of TrkA receptors in axons. Anterograde TrkA delivery and exocytosis into axon growth cones is enhanced by nerve growth factor (NGF), acting locally on distal axons. Perturbing endocytic recycling attenuated NGF-dependent signaling and axon growth while enhancing recycling conferred increased neuronal sensitivity to NGF. Our results reveal regulated transcytosis as an unexpected mode of Trk trafficking that serves to rapidly mobilize ready-synthesized receptors to growth cones, thus providing a positive feedback mechanism by which limiting concentrations of target-derived neurotrophins enhance neuronal sensitivity.

\section{Introduction}

Polarized membrane trafficking of signaling receptors is critical for developing neurons to respond to extracellular stimuli mediating growth, guidance, and neuronal survival. The family of tropomyosin-related kinases (Trk) receptors provides a prominent example of trophic factor receptors that undergo longdistance axonal trafficking to regulate growth and survival of developing neurons (Zweifel et al., 2005). A key mechanism by which the prototypical neurotrophin, nerve growth factor (NGF), secreted by peripheral target tissues, provides trophic support to sympathetic neurons is by regulating endocytosis and retrograde trafficking of NGF:TrkA complexes in signaling endosomes from axon terminals to cell bodies (Delcroix et al., 2003; Ye et al., 2003; Heerssen et al., 2004; Zweifel et al., 2005). However, the neurotrophin-mediated developmental processes of axon growth, guidance, and neuronal survival must also place an enormous demand on rapid axonal targeting of Trk receptors to ensure sensitive functional responses. Currently, little is known about the membrane trafficking mechanisms regulating proper localization of Trk receptors in axons.

Membrane proteins are often delivered to axons via the secretory pathway (Horton and Ehlers, 2003). Proteins, after synthesis

Received March 31, 2009; revised July 31, 2009; accepted Aug. 11, 2009.

This work was supported with funds from the National Institutes of Health Grant R01 MH080738 and a Whitehall Foundation award (R.K.). We are grateful to D. D. Ginty, A. Riccio, B. Wendland, E. Lei, and H. Zhao for insightful comments on this manuscript and to all members of the Kuruvilla, Hattar, and Zhao laboratories for helpful discussions on this study. We thank D. D. Ginty for providing TrkA-GFP and TrkB:TrkA plasmids, R. Y. Tsien for mcherry plasmid, M. Ehlers for EGFP-Rab11a-WT and EGFP-Rab11a-S25N plasmids, and J. E. Pessin for the Dyn-K44A adenovirus. We also thank Francis Lee for help with the FLAG antibody feeding assays and the Integrated Imaging Center (IIC) Hopkins Biology for technical support in imaging analyses.

Correspondence should be addressed to Rejji Kuruvilla, Department of Biology, Johns Hopkins University, Baltimore, MD 21218. E-mail: rkuruvilla@jhu.edu.

D0I:10.1523/JNEUROSCI.1542-09.2009

Copyright $\odot 2009$ Society for Neuroscience $\quad 0270-6474 / 09 / 2911674-12 \$ 15.00 / 0$ in the rough endoplasmic reticulum (ER) and undergoing maturation in the ER-Golgi network in neuronal cell bodies, are shipped directly to axons in Golgi-derived vesicles. However, in some cases, axonal targeting is accomplished by a more circuitous endocytosis-dependent mechanism called transcytosis in which proteins are initially delivered to somatodendritic compartments and then endocytosed and transported anterogradely for insertion into axon terminals (Horton and Ehlers, 2003). Transcytosis has been best characterized in polarized epithelial cells, including hepatocytes and enterocytes, in which endocytic trafficking from basolateral to apical surfaces is the primary mode for delivery of newly synthesized apical membrane proteins (Bastaki et al., 2002; Tuma and Hubbard, 2003). So far, transcytotic delivery from neuronal soma surfaces to axons has been demonstrated for only a limited number of membrane proteins, including L1/neuronglia cell adhesion molecule (NgCAM) (Wisco et al., 2003), a cell adhesion molecule important for axon guidance, transferrin ( $\mathrm{Tf}$ ) receptor (Hémar et al., 1997), which regulates cellular iron homeostasis, and the type 1 cannabinoid receptor $\mathrm{CB}_{1} \mathrm{R}$ (Leterrier et al., 2006), a highly abundant G-protein-coupled receptor in the nervous system implicated in modulating synaptic plasticity. However, the implications of transcytosis on receptor signaling and function have remained unclear.

Here, we show that Trk receptors undergo transcytosis in developing sympathetic neurons, which involves the endocytic removal of biochemically mature receptors from neuronal cell bodies and retargeting them to axons through recycling endosomes. We provide evidence that neurotrophins acting on axon terminals of compartmentalized cultures can recruit their Trk receptors to their sites of action via transcytosis. Perturbing endocytic recycling attenuated NGF-dependent signaling and functional responses, whereas enhancing recycling increased neuronal responsiveness to NGF. Together, our results suggest 
that this previously uncharacterized mode of TrkA trafficking allows neurons to adjust their sensitivity to the limiting concentrations of NGF found in vivo.

\section{Materials and Methods}

\section{DNA and adenoviral constructs}

Enhanced green fluorescent protein (EGFP)-Rab11a-wild-type (WT) and EGFP-Rab11a-S25N plasmids were a gift from Dr. Michael Ehlers (Duke University, Durham, NC). EGFP-Rab11a-Q70L was generated from EGFP-Rab1la-WT using site-directed mutagenesis (QuikChange; Stratagene). All EGFP-Rab11a constructs were subcloned into pshuttlecytomegalovirus (CMV) vector (Stratagene). The mcherry-Rab1la construct was generated by subcloning mcherry (kindly provided by Dr. Roger Tsien, University of California San Diego, La Jolla, CA) with Rab1la construct into pshuttle-CMV vector. The N-terminal FLAG tag was placed on the $5^{\prime}$ end of TrkB:TrkA chimeric receptor (provided by Dr. David Ginty, Johns Hopkins University, Baltimore, MD) by PCR. TrkB:A chimeric receptor has amino acid residues 1-423 belonging to the extracellular domain of TrkB and residues 424-809 belonging to the transmembrane and cytoplasmic domains of TrkA. FLAG-TrkB:A was subcloned into pAdTrack-CMV shuttle vector (Stratagene), which also expresses GFP. TrkA-GFP (gift from Dr. David Ginty) and farnesylated EGFP (Clontech) were cloned into pshuttle-CMV expression vectors. Replication-incompetent recombinant adenoviral constructs were generated for EGFP-Rab1 1 a constructs and the FLAG-TrkB:A chimeric receptor using the AdEasy adenoviral vector system (Stratagene). Recombinant viral backbones including the genes of interest were transfected into HEK 293 cells (American Type Culture Collection) using Lipofectamine (Invitrogen). High-titer virus stocks were generated using a $\mathrm{CsCl}$ gradient. The recombinant adenoviral construct encoding dominant-negative dynamin-1 (Dyn-1-K44A) was a gift from Dr. Jeffrey E. Pessin (Albert Einstein College of Medicine, Bronx, NY).

\section{Sympathetic neuron culture and transfection}

Superior cervical ganglia were dissected from postnatal day 0.5 (P0.5) Sprague Dawley rats and grown in mass or compartmentalized cultures as described previously (Kuruvilla et al., 2004). Cells were maintained in culture with high-glucose DMEM media supplemented with $10 \%$ fetal bovine serum (FBS), penicillin/streptomycin (1 U/ml), and NGF (50$100 \mathrm{ng} / \mathrm{ml}$ ) purified from male mouse submaxillary glands as described previously (Mobley et al., 1976). For immunocytochemistry, cells were plated on poly-D-lysine- $(1 \mu \mathrm{g} / \mathrm{ml}$; Sigma)-coated coverslips. To withdraw NGF from the cultures, cells were washed with DMEM and placed in high-glucose DMEM containing 0.5\% FBS with 1:1000 anti-NGF (Sigma) and boc-aspartyl( $O$-methyl)-fluoromethylketone (BAF) (50 $\mu \mathrm{M}$; MP Biomedicals) for $48 \mathrm{~h}$. Cells were electroporated using Cellaxess CX1 system (Cellectricon) with $200 \mathrm{ng} / \mathrm{ml}$ DNA according to the instructions of the manufacturers. For adenoviral infections, neuronal cultures were infected with high-titer CsCl-purified adenoviruses for $12 \mathrm{~h}$ as described previously (Kuruvilla et al., 2000).

\section{Cell-surface biotinylation assay}

Internalization of TrkA receptors. Two days before the biotinylation assay, NGF was withdrawn from mass cultures as described above. Neurons were biotinylated with a reversible membrane-impermeable form of biotin (EZ-Link NHS-S-S-biotin, $1.5 \mathrm{mg} / \mathrm{ml}$ in $1 \times$ PBS; Pierce Chemical) at $4^{\circ} \mathrm{C}$ for $25 \mathrm{~min}$ (Kuruvilla et al., 2004). Neurons were washed briefly with $1 \times$ PBS containing $50 \mathrm{~mm}$ glycine (Sigma) to remove remaining unconjugated biotin. Cells were moved to $37^{\circ} \mathrm{C}$ to promote internalization under the appropriate conditions for $30 \mathrm{~min}$. To block recycling, cells were treated with monensin (10 $\mu \mathrm{M}$; Sigma) for 30 min during the internalization process. Neurons were returned to $4^{\circ} \mathrm{C}$, and the remaining biotinylated surface receptors were stripped of their biotin tag with 50 mu glutathione (Sigma). After this stripping process, cells were washed twice with $50 \mathrm{~mm}$ iodoacetamide (Sigma) to quench excess glutathione. Neurons were lysed with $500 \mu \mathrm{l}$ of radioimmunoprecipitation assay (RIPA) solution (50 mм Tris- $\mathrm{HCl}, 150 \mathrm{~mm} \mathrm{NaCl}, 1$ mm EDTA, 1\% NP-40, $0.25 \%$ deoxycholate), and supernatants were subjected to precipitation with $50 \mu$-immobilized neutravidin-agarose beads (Pierce Chemical) and immunoblotting with a TrkA antibody (Millipore Bioscience Research Reagents).

Surface TrkA levels. Neurons were briefly treated with a 5 min pulse of $\mathrm{NGF}(100 \mathrm{ng} / \mathrm{ml})$ in the presence or absence of monensin $(10 \mu \mathrm{M})$ at $37^{\circ} \mathrm{C}$ and then quickly moved to $4^{\circ} \mathrm{C}$. Surface levels of TrkA were assessed by cell-surface biotinylation at $4^{\circ} \mathrm{C}$ for $30 \mathrm{~min}$, neutravidin precipitation, and TrkA immunoblotting.

Transcytosis of TrkA receptors in compartmentalized cultures. Approximately 250,000-300,000 sympathetic neurons were grown per compartmentalized culture chamber for 7-10 d in vitro (DIV) until axonal projections into the side chambers were evident. Neurons were starved of NGF for $2 \mathrm{~d}$, and surface TrkA receptors in cell body compartments were biotinylated with a membrane-impermeable biotin (EZ-Link NHS-S-Sbiotin) at $4^{\circ} \mathrm{C}$ for $25 \mathrm{~min}$. After incubating the cultures at $37^{\circ} \mathrm{C}$ for $4 \mathrm{~h}$ in the presence or absence of NGF (100 ng/ml) added only to axons, lysates were harvested from cell body and axonal compartments separately and subjected to neutravidin precipitation and TrkA immunoblotting.

\section{Live-cell antibody feeding assay}

Trk receptor internalization. Sympathetic neurons were infected with adenoviral vectors expressing GFP or FLAG-TrkB:A chimeric receptors. Infected neurons were identified by GFP expression. NGF was withdrawn from the cultures without adding the anti-NGF antibody, and cells were incubated with mouse anti-FLAG antibody (M2, $4.2 \mu \mathrm{g} / \mathrm{ml}$; Sigma) or Fab fragments derived from the FLAG antibody $(10 \mu \mathrm{g} / \mathrm{ml}$; prepared according to the instructions from Pierce Chemical) for $30 \mathrm{~min}$ at $4^{\circ} \mathrm{C}$ in PBS. Excess antibody was washed off, and cells were moved to $37^{\circ} \mathrm{C}$ for $30 \mathrm{~min}$ under various conditions for internalization. Cells were then washed quickly with PBS and immediately fixed with $4 \%$ paraformaldehyde (PFA) in PBS for $30 \mathrm{~min}$ at room temperature. Cells were then permeabilized with $0.1 \%$ Triton X-100/1\% BSA $/ 1 \times$ PBS, incubated with fluorescently conjugated anti-mouse secondary antibody for $1 \mathrm{~h}$, and then mounted on slides with Antifade Gold (Invitrogen). Images representing $1 \mu \mathrm{m}$ optical slices were acquired using a Carl Zeiss LSM 510 confocal scanning microscope equipped with argon $(458-488 \mathrm{~nm})$ and helium/neon (543-633) lasers. The same confocal acquisition settings were applied to all images taken from a single experiment. Threshold settings for green and red scans were determined, and the integrated fluorescence values for each channel were quantified. For internalization experiments using M2 anti-FLAG antibody, internalization was quantified as the ratio of anti-FLAG immunofluorescence (red) that colocalized with cytoplasmic GFP (green) relative to the total anti-FLAG immunofluorescence. Weighted coefficients of colocalization between the antiFLAG and GFP fluorescence were determined by LSM Image Examiner program (Carl Zeiss).

Recycling assay. Sympathetic neurons grown in compartmentalized cultures and expressing FLAG-tagged TrkB:A receptors were incubated with Alexa-647-conjugated $\mathrm{Ca}^{2+}$-sensitive monoclonal anti-FLAG antibody (M1 antibody, $4.2 \mu \mathrm{g} / \mathrm{ml}$; Sigma) in PBS supplemented with $1 \mathrm{~mm}$ $\mathrm{CaCl}_{2}$ separately in cell body and axon compartments for $30 \mathrm{~min}$ at $4^{\circ} \mathrm{C}$. In Figure $1 G$, "Surface" culture dishes were left at $4^{\circ} \mathrm{C}$, whereas "Internalized" and "Recycled" dishes were moved to $37^{\circ} \mathrm{C}$ for $30 \mathrm{~min}$ to allow for internalization. "Internalized" and "Recycled" dishes were then quickly washed three times with ice-cold $1 \times$ PBS containing 1 mM EDTA to strip surface-bound FLAG antibodies that had not internalized. Media containing Alexa-546-conjugated anti-mouse secondary antibody was added to all plates, and "Internalized" and "Recycled" dishes were returned to $37^{\circ} \mathrm{C}$ whereas "Surface" dishes remained at $4^{\circ} \mathrm{C}$, for another 30 min. Cultures were quickly washed with ice-cold $1 \times$ PBS and immediately fixed with $4 \%$ PFA in $1 \times$ PBS. Images were acquired using a Carl Zeiss LSM 510 confocal scanning microscope. Optical sections, $1 \mu \mathrm{m}$, were taken, and the same confocal acquisition settings were applied to all images taken from a single experiment. In the "Surface" conditions, surface receptors were quantified as the number of pixels double positive for Alexa-647 and Alexa-546 fluorescence per square micrometer in each cell body or axon (for axons, measurements were taken from a stretch of axon equal to 100-250 $\mu \mathrm{m}$ length). In "Internalized" conditions, internalized receptors were calculated as the number of Alexa-647 fluorescent pixels per square micrometer of cell body or axon. Internalized receptors 
were then expressed as a percentage of the total surface receptors for $20-30$ cells per experiment. In "Recycled" conditions, recycled receptors were calculated as described previously. The percentage of recycled receptors was calculated using the following formula: $(E-Z) /$ $(C-Z) \times 100$, where $E$ is the colocalization coefficient for Alexa-647-FLAG- and Alexa546-conjugated secondary antibody fluorescence in the "Recycled" condition. $Z$ is the colocalization coefficient for Alexa-647-FLAG and Alexa-546 fluorescence in the "Internalized" condition. $C$ is colocalization coefficient for Alexa-647-FLAG and Alexa-546 fluorescence in "Surface" condition.

Transcytosis of FLAG-TrkB:A receptors in compartmentalized cultures. Sympathetic neurons expressing FLAG-TrkB:A chimeric receptors were grown in compartmentalized culture chambers assembled on collagen-coated glass coverslips for 7-10 DIV until axonal projections were evident in the side compartments. After withdrawing NGF from the culture media, surface chimeric receptors residing in cell body compartments were labeled under livecell conditions with mouse anti-FLAG antibody (M2, $4.2 \mu \mathrm{g} / \mathrm{ml})$ or FLAG Fab $(10 \mu \mathrm{g} / \mathrm{ml})$ for indicated time periods at $37^{\circ} \mathrm{C}$. Cultures were washed, fixed, permeabilized, and incubated with fluorescently labeled anti-mouse secondary antibody. Chambers were then detached from the coverslips, ensuring that the cells remained attached. Coverslips were mounted on glass slides, and images were acquired with Carl Zeiss LSM 510 confocal microscope. For colocalization experiments with Rab11, neurons were incubated overnight with rabbit antiRab1la antibody (1:1000; Zymed), rabbit antiRab4 (1:500; ab13252; Abcam), or mouse anti-Rab7 (1:5000; clone Rab7-117; Sigma). For colocalization experiments with Tf, 50 $\mu \mathrm{g} / \mathrm{ml}$ Alexa-546-conjugated human Tf (Invitrogen) was added exclusively to the cell body compartments of compartmentalized cultures along with anti-FLAG antibody. Chambers were incubated for $4 \mathrm{~h}$ at $37^{\circ} \mathrm{C}$, washed several times with PBS, and then fixed and permeabilized. Anti-FLAG was detected as described above.

Time-lapse imaging of axonal transport and total internal reflection fluorescence analyses

Rablla and TrkA axonal transport. Sympathetic neurons were grown on poly-lysinecoated glass-bottom dishes (MatTek). Cells were electroporated using Cellaxess CX1 system with $200 \mathrm{ng} / \mathrm{ml}$ each of mcherry-Rablla and TrkA-GFP DNA constructs. Neurons were imaged in Leibovitz L-15 media (Invitrogen) supplemented with $0.5 \%$ FBS. Axonal transport of mcherry-Rab1la and TrkA-GFP was visualized using 3-I Marianas wide-field live-cell imaging workstation (Intelligent Imaging Innovations) equipped with dual Cascade II 512 EM cameras for simultaneous two-channel acquisition. Images were acquired using $100 \times$ objective (1.45 numerical aperture oil-immersion $\alpha$-plan-fluoar; Carl Zeiss) every 2 s over 200 frames per movie and
A
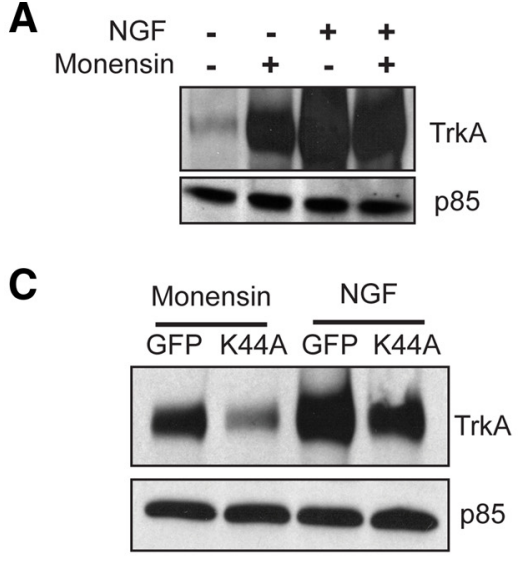

$\mathbf{F}$
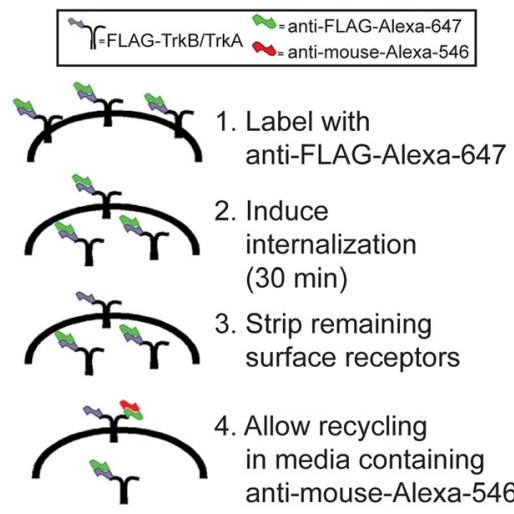

4. Allow recycling in media containing anti-mouse-Alexa-546 (30 min)
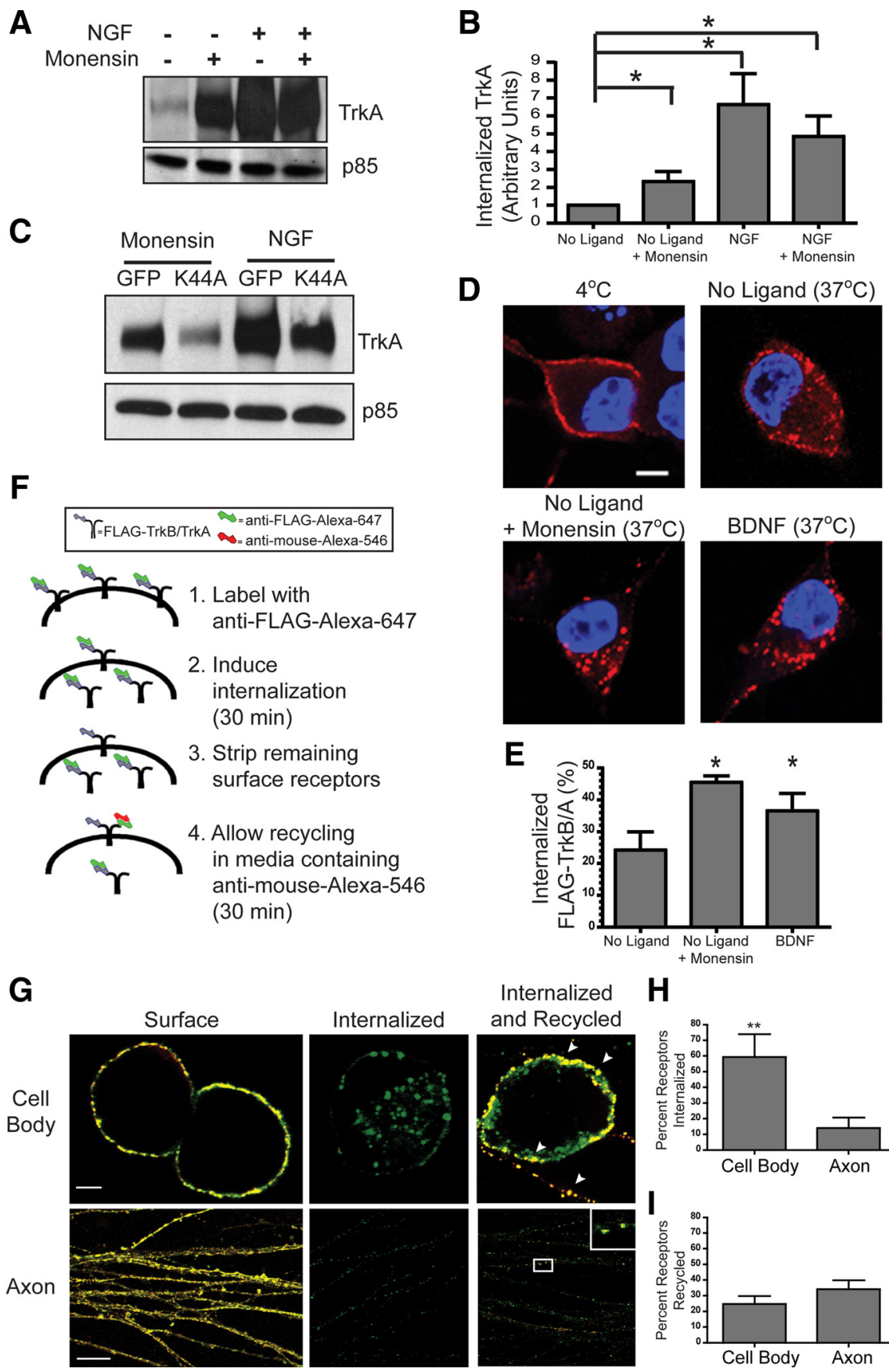

No Ligand
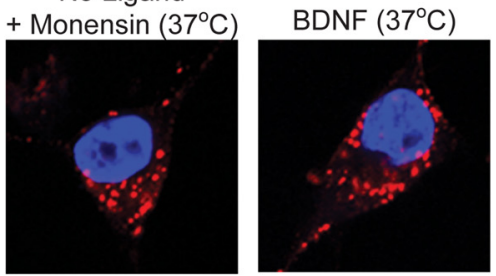

E

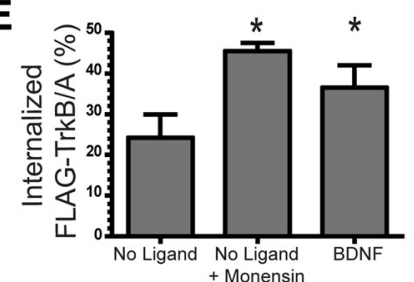

Internalized

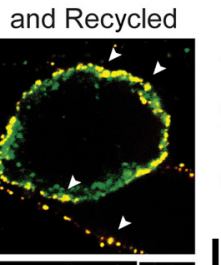

$\mathrm{H}$

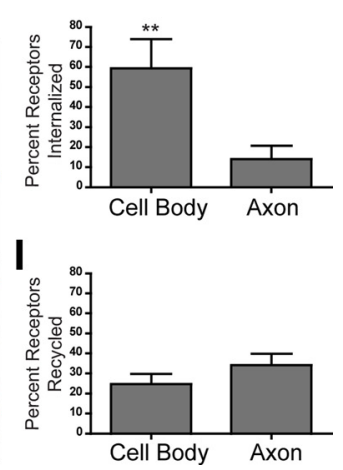

Figure 1. Trk receptors undergo constitutive endocytosis and recycling in sympathetic neurons. $A$, Constitutively internalized TrkA receptors are sequestered intracellularly during blocking recycling with monensin $(10 \mu \mathrm{M})$. Membrane proteins were subjected to cell-surface biotinylation. Internalized TrkA receptors were detected by surface stripping of biotin, neutravidin precipitation, and TrkA Western blotting. $\boldsymbol{B}$, Densitometric quantification of the results shown in $\boldsymbol{A}$. Results are the mean \pm SEM from seven independent experiments. ${ }^{*} p<0.05, t$ test. $C$, Monensin-dependent intracellular accumulation of surface TrkA receptors is attenuated in neurons expressing Dyn-K44A. Cell-surface biotinylation assay was performed in neurons infected with adenoviral vectors expressing GFP and Dyn-K44A, in the presence of monensin or NGF. Normalization for protein amounts in $\boldsymbol{A}$ and $\boldsymbol{C}$ was performed by immunoblotting neuronal lysates for p85 subunit of PI3K. $D$, Live antibody feeding assays in neurons expressing FLAG-TrkB:A chimeric receptors show subcellular localization of receptors under the conditions indicated. Scale bar, $5 \mu \mathrm{m}$. $\boldsymbol{E}$, Quantification of internal accumulation of chimeric receptors under the various conditions indicated in $\boldsymbol{D}$, by assessing the proportion of colocalization of FLAG immunofluorescence with that of GFP (data not shown), which is coexpressed in infected neurons and is cytoplasmic. Values have been corrected by subtracting any colocalization observed at $4^{\circ} \mathrm{C}$. Results are the mean \pm SEM from five independent experiments. ${ }^{*} p<0.05$ relative to No Ligand condition, ANOVA, followed by a Tukey's post hoc test. $\boldsymbol{F}$, Schematic of a live-cell ratiometric assay to measure receptor internalization and recycling. G, Spatial analyses of constitutive Trk trafficking in neurons. Representative images of surface, constitutive internalized, and recycled chimeric receptors in cell bodies (top row) and axons (bottom row), as assessed by the live-cell ratiometric assay performed independently in cell body and axon compartments in compartmentalized neuronal cultures. Scale bars: Cell Body, $5 \mu \mathrm{m}$; Axon, $20 \mu \mathrm{m}$. Graphs represent quantification of Trkinternalization $(\boldsymbol{H})$ and recycling $(\boldsymbol{I})$ from seven independent experiments. Values are means $\pm \mathrm{SEM} ;{ }^{* *} p=0.02, t$ test. 
analyzed as described previously (Deinhardt et al., 2006). The distance traveled by double-positive carriers between two consecutive frames, defined as a single movement, was used to determine instantaneous speed. Carriers were analyzed and tracked using NIH ImageJ. Speeds were binned into $0.2 \mu \mathrm{m} / \mathrm{s}$ and plotted using Prism software (GraphPad Software). Kymographs and movies were generated with Slidebook (Intelligent Imaging Innovations).

NGF-induced TrkA-GFP surface recruitment. Total internal reflection fluorescence (TIRF) analysis of Cos-1 cells and sympathetic neurons expressing TrkA-GFP or farnesylated EGFP was performed on the Marianas Live Cell Imaging Workstation using a Carl Zeiss TIRF slider and a $100 \times$ objective (1.45 numerical aperture, $\alpha$-plan-fluoar; Carl Zeiss). Images were taken every $2 \mathrm{~s}$ for 200 frames, and change in evanescence-field fluorescence $(\triangle \mathrm{EFF})$ was calculated as described previously (Bezzerides et al., 2004) using NIH ImageJ.

BDNF-induced FLAG-TrkB:A surface recruitment. Sympathetic neurons were infected with adenovirus expressing FLAG-TrkB:A chimeric receptors. Neurons were incubated with the calcium-sensitive mouse anti-FLAG antibody (M1, $4.2 \mu \mathrm{g} / \mathrm{ml}$; Sigma) for $30 \mathrm{~min}$ at $4^{\circ} \mathrm{C}$. Cells were washed and moved to $37^{\circ} \mathrm{C}$ for $30 \mathrm{~min}$ to allow for receptor internalization. EDTA (at $1 \mathrm{~mm}$ ) washes were used to strip remaining surface receptors of anti-FLAG antibody, and cells were then treated with a 5 min pulse of BDNF (100 ng/ml) in culture media containing Alexa-546-conjugated anti-mouse secondary antibody. Cells were quickly washed with cold PBS and fixed with 4\% PFA. Images were taken using LSM 510 confocal microscope.

\section{Axon growth and neuronal survival}

Sympathetic neurons grown in compartmentalized culture chambers were infected with adenoviral constructs expressing GFP, EGFPRab1la-S25N, and EGFP-Rab11a-Q70L. Axon growth (micrometers per day) in response to NGF added at the indicated concentrations only to axon compartments was measured as described previously (Kuruvilla et al., 2004). To assess neuronal survival, sympathetic neurons from P0.5 rats grown on collagen-coated coverslips for $12 \mathrm{~h}$ were infected with adenovirus expressing FLAG-TrkB:A receptors. Neurons were grown in the presence of $10 \mathrm{ng} / \mathrm{ml} \mathrm{NGF}$ for another $48 \mathrm{~h}$. Neurons were then washed and cultured in the presence of BDNF $(25 \mathrm{ng} / \mathrm{ml})$ and/or antiFLAG antibody (M2, $4.2 \mu \mathrm{g} / \mathrm{ml})$ for $72 \mathrm{~h}$ with the addition of anti-NGF (Sigma). Cells were fixed, permeabilized, and incubated with Hoechst 33258 (1:1000) in PBS for $1 \mathrm{~h}$. Neurons with pyknotic, condensed, or fragmented nuclei were scored as dead as described previously (Kuruvilla et al., 2004). Percentage survival is expressed relative to $10 \mathrm{ng} / \mathrm{ml} \mathrm{NGF} \mathrm{(100 \% ).}$

\section{Immunoprecipitation, immunoblotting, and antibodies}

Neurons were lysed with RIPA solution, and lysates were subjected to immunoprecipitation with anti-phosphotyrosine (P-Tyr) (PY-20; Sigma), anti-FLAG (M2; Sigma), or TrkB (BD Biosciences) and incubated with Protein-A agarose beads (Santa Cruz Biotechnology). Immunoblotting analyses of sympathetic neuron lysates were performed as described previously (Kuruvilla et al., 2004). The following antibodies were used for immunoblotting: TrkA (Millipore Bioscience Research Reagents), P-Tyr (PY20; Sigma), and P-Akt (Ser473) and P-Erk1/2 (Thr202/Tyr204) (Cell Signaling Technology). Normalization for protein amounts was done by stripping immunoblots and reprobing for the p85 subunit of phosphatidylinositol 3-kinase (Upstate Biotechnology). Blots were visualized with ECL Plus Detection Reagent (GE Healthcare) and scanned with a Typhoon 9410 Variable Mode Imager (GE Healthcare). Densitometry analysis was performed with ImageQuant software (Molecular Dynamics).

\section{Statistical analyses}

Prism software was used for statistical analyses, and all data passed normality tests. All Student's $t$ tests were performed assuming Gaussian distribution, two-tailed, unpaired, a confidence interval of $95 \%$. Oneway or two-way ANOVA analyses were performed when more than two groups were compared.

\section{Results}

Trk receptors undergo constitutive endocytosis and recycling in developing sympathetic neurons

Previous studies had indicated that Trk receptors undergo endocytosis predominantly in a ligand-dependent manner (Grimes et al., 1996; Kuruvilla et al., 2004; Chen et al., 2005). We found that TrkA receptors undergo constitutive cycling between the plasma membrane and intracellular endosomes in sympathetic neurons. In a cell-surface biotinylation assay to follow the fate of surface TrkA receptors, NGF stimulation leads to robust internalization of TrkA receptors (Fig. $1 A, B$ ), as reported previously. Interestingly, blocking endocytic recycling with the recycling inhibitor monensin (Basu et al., 1981) resulted in significant intracellular accumulation of Trk receptors in the absence of any ligand (Fig. $1 A, B)$, suggesting that surface Trk receptors undergo constitutive internalization and recycling back to the plasma membrane. Blocking recycling in the presence of NGF did not induce any additional intracellular accumulation of TrkA receptors beyond that elicited by NGF alone (Fig. $1 A, B$ ). Monensin-dependent intracellular accumulation of TrkA is attenuated in neurons expressing a dominant-negative form (Dyn-K44A) of the GTPase dynamin (Ye et al., 2003), which functions in vesicle scission during endocytosis (Fig. 1C), suggesting that constitutive trafficking of TrkA receptors uses components of the cellular endocytic machinery.

To visualize Trk trafficking in neurons, we also performed live-cell antibody feeding assays in neurons expressing FLAGtagged chimeric receptors that have the extracellular domain of TrkB and the transmembrane and intracellular domains of TrkA (FLAG-TrkB:A). Sympathetic neurons do not normally express TrkB (Atwal et al., 2000), but neurons expressing chimeric receptors showed signaling responses to the TrkB ligand, BDNF, in a manner similar to endogenous TrkA receptors stimulated with NGF (supplemental Fig. 1, available at www.jneurosci.org as supplemental material). The chimeric receptors showed no crossactivation with endogenous TrkA receptors (supplemental Fig. 1, available at www.jneurosci.org as supplemental material). Livecell immunocytochemistry was performed using an antibody directed against the extracellular FLAG epitope of chimeric Trk receptors. We did not observe any signaling or survival responses in neurons treated with antibody alone (supplemental Fig. 1, available at www.jneurosci.org as supplemental material), indicating that the antibodies were not autoactivating. Live-cell immunocytochemistry revealed exclusively surface localization of the receptors at $4^{\circ} \mathrm{C}$, a temperature at which little protein trafficking occurs (Fig. $1 D$ ). However, at $37^{\circ} \mathrm{C}$, the permissive temperature for trafficking, we observed a punctate intracellular localization of Trk receptors, which could be enhanced by either blocking recycling or adding ligand (Fig. $1 D, E$ ). Because the FLAG IgG antibodies bind to the extracellular region of FLAG-TrkB:A receptors and could potentially induce receptor dimerization and subsequent internalization, we also used, in uptake assays, FLAG Fab fragments that retain the ability to bind antigen without the potential for nonspecific receptor clustering. FLAG-tagged receptors labeled with Fab fragments showed similar internalization and trafficking as those labeled with IgG (supplemental Fig. 2 , available at www.jneurosci.org as supplemental material). Together with our findings that the FLAG antibodies by themselves do not induce any signaling or survival responses, these results indicate that internalization observed with live antibody-feeding assays are not an artifact of antibody-induced receptor clustering. Control GFP-expressing sympathetic neurons showed little to no 
FLAG-immunoreactivity with either the IgG or Fab fragments (supplemental Fig. 2, available at www.jneurosci.org as supplemental material), pointing to the specificity of uptake of the FLAG antibody in FLAG-TrkB:A-expressing neurons. Together, these results demonstrate a previously unappreciated mode of ligand-independent trafficking of Trk receptors, in which receptors are constitutively endocytosed and recycled in sympathetic neurons.

\section{Constitutive endocytosis of Trk receptors occurs predominantly in cell bodies}

Given the polarized morphology of neurons, we asked whether constitutive trafficking of Trk receptors differs between cell bodies and axons. Neurons were grown in compartmentalized cultures and modified live-cell antibody feeding assay (Chen et al., 2005) was used to directly monitor internalization and recycling of cell-surface FLAG-TrkB:A receptors labeled with Alexa-647FLAG antibodies independently in cell bodies and axons (Fig. $1 F)$. After an incubation period of $30 \mathrm{~min}$, which allowed for the internalization of labeled receptors, surface-bound antibodies were stripped, leaving antibodies bound only to the internalized pool of receptors (Fig. 1G). Additional incubation of cell body and axon compartments for an additional 30 min with Alexa-546 secondary antibodies tagged receptors that recycled to the cell surface (Fig. 1G). Quantification by ratiometric analyses showed that the percentage of surface TrkA receptors that undergo ligand-independent internalization is significantly higher in neuronal cell bodies $(59.31 \pm 14.7 \%)$ than in axons $(14.05 \pm 6.73 \%)$ ( $p=0.02, t$ test; $n=7$ independent experiments) (Fig. $1 H$ ). However, of the receptors that internalize, recycling occurs to a similar extent in cell bodies $(24.68 \pm 5.18 \%)$ and axonal $(34.18 \pm$ $5.70 \%)$ compartments $(p=0.24, t$ test; $n=7$ independent experiments) (Fig. 1I). These results indicate that ligandindependent internalization of Trk receptors occurs predominantly in neuronal cell bodies but is minimal in axons.

\section{Neurotrophins acting on axons promote anterograde transcytosis of Trk receptors}

We hypothesized that constitutive endocytosis of Trk receptors in neuronal cell bodies would maintain a dynamic intracellular receptor pool that could be mobilized to axons during neurotrophin stimulation. This would be a way to transport Trk receptors to axons to modulate responses to targetderived neurotrophins without the need for de novo synthesis. To test this hypothesis, we used live-cell antibody feeding in compartmentalized cultures to selectively label and follow Trk receptors originating from surfaces of cell bodies. Neurons expressing FLAG-TrkB:A receptors were grown in compartmentalized cultures, and surface receptors were labeled with anti-FLAG antibody exclusively in cell body compartments (Fig. 2A). Labeling with a fluorescent secondary antibody revealed the presence of FLAG-antibody-bound receptors in axons after a $4 \mathrm{~h}$, but not $30 \mathrm{~min}$, incubation period (Fig. $2 \mathrm{~B}$ ). Because antibody-tagged receptors could only have originated from surfaces of neuronal cell bodies, these results provide direct evidence for anterograde transcytosis of Trk receptors in sympathetic neurons.

To test whether target-derived neurotrophins regulate transcytosis of Trk receptors, we assessed the effects of BDNF added exclusively to axon compartments of compartmentalized cultures on anterograde trafficking of Trk receptors originating from neuronal soma surfaces. BDNF treatment of axons markedly enhanced the levels of anti-FLAG-labeled chimeric Trk re- ceptors in axons after $4 \mathrm{~h}$, with a $5.93 \pm 1.14$-fold increase compared with unstimulated neurons (Fig. $2 B)(p=0.04, t$ test; $n=3$ independent experiments). Similar results were obtained when neuronal cell bodies were labeled with anti-FLAG Fab fragments (supplemental Fig. 2, available at www.jneurosci.org as supplemental material).

To determine whether endogenous TrkA receptors in sympathetic neurons undergo a similar process of internalization from neuronal cell bodies and anterograde transport, we biotinylated membrane proteins selectively in cell body compartments of compartmentalized cultures. Neutravidin precipitation followed by Western blot analysis of cell lysates from the cell bodies and axonal compartments showed the presence of biotinylated TrkA receptors in axons after a $4 \mathrm{~h}$ incubation period (Fig. 2C), demonstrating that endogenous TrkA receptors in sympathetic neurons undergo transcytosis. The TrkA receptor initially synthesized in the rough endoplasmic reticulum is in a precursor $110 \mathrm{kDa}$ form that, in the course of reaching the plasma membrane, acquires a $30 \mathrm{kDa}$ sugar moiety to become the mature glycosylated form (Jullien et al., 2003). Biotinylated receptors on SDS-PAGE gels corresponded to the $\sim 140 \mathrm{kDa}$ form of the TrkA receptors, indicating that it is the biochemically mature form of the receptor that is available on neuronal cell bodies for surface labeling with biotin and subsequently endocytosed and anterogradely transported to axons. Treatment of axon terminals with NGF enhanced axonal transcytosis of TrkA receptors by $1.32 \pm 0.07$-fold compared with unstimulated conditions (Fig. $2 C)(p=0.03, t$ test; $n=4$ independent experiments). The difference between the levels of BDNF-induced axonal transcytosis of FLAG-TrkB:A receptors $(5.93 \pm 1.14$-fold increase) versus NGF-induced transport of endogenous TrkA receptors (1.32 \pm 0.07 -fold increase) might be explained by that a more sensitive microscopy-based assay was used to detect transcytosing receptors in the first case compared with Western blotting of biotinylated receptors in the second. In addition, for the fluorescence-based assay, neurons were grown in Camp10 Teflon dividers in which the distance between neuronal cell bodies and distal axonal processes is $\sim 1 \mathrm{~mm}$. However, for the biotinylationbased assay, neurons were cultured in larger biochemistry chambers in which the distance between cell bodies and distal processes is $\sim 3-5 \mathrm{~mm}$. Given that, in both cases, appearance of anterogradely transported Trk receptors was assessed after $4 \mathrm{~h}$, more Trk receptors could have accumulated over time in the shorter axons in the Camp10 chambers compared with biochemistry chambers.

Axonal transport of biotinylated TrkA receptors from cell body to axonal compartments is inhibited by expression of DynK44A (Fig. 2D) (60 $\pm 0.13 \%$ decrease compared with control GFP-expressing neurons; $p=0.04, t$ test; $n=3$ independent experiments), indicating that anterograde movement of Trk receptors is endocytosis dependent and is not attributable to lateral diffusion of receptors along the plasma membrane. To determine whether this mode of trafficking contributes significantly to axonal targeting of TrkA receptors, we examined the effect of DynK44A on axonal levels of TrkA receptors. Blockade of endocytosis reduced axonal levels of TrkA receptors by $43 \pm 0.09 \%$ (Fig. 2E) ( $p=0.04, t$ test; $n=3$ independent experiments), without affecting total TrkA expression in neurons (Fig. $2 F$ ) or surface levels of TrkA receptors on neuronal cell bodies (supplemental Fig. 2, available at www.jneurosci.org as supplemental material). Together, these results suggest that target-derived neurotrophins acting on axon terminals recruit a considerable proportion of Trk receptors to their sites of action by anterograde transcytosis. 
A

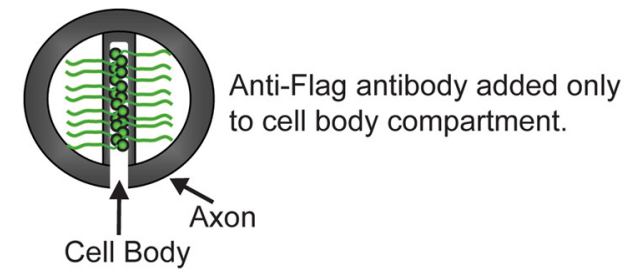

B

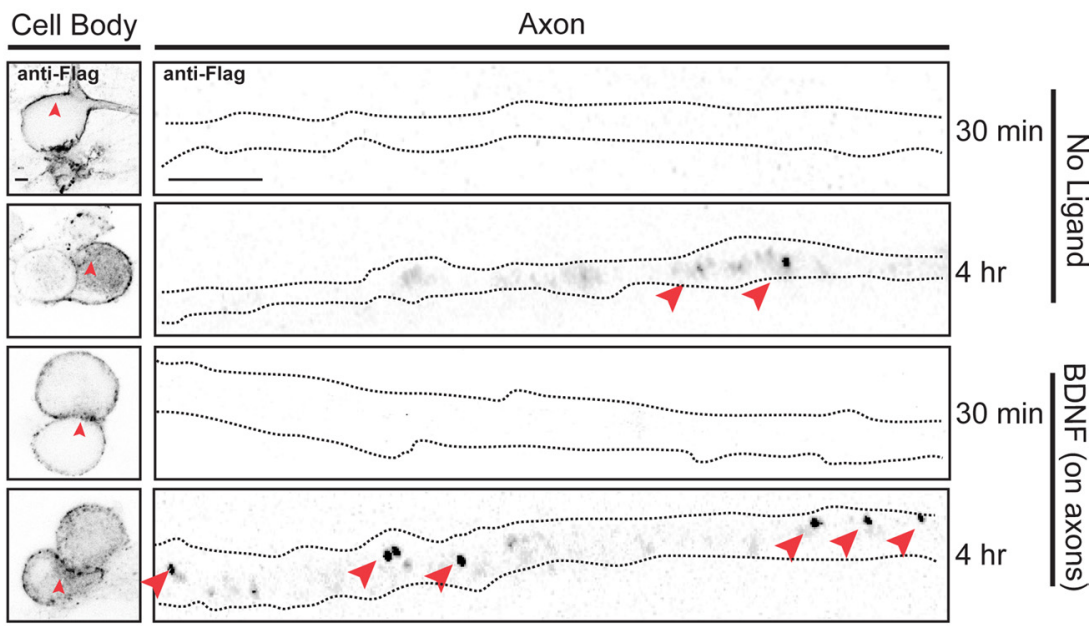

C

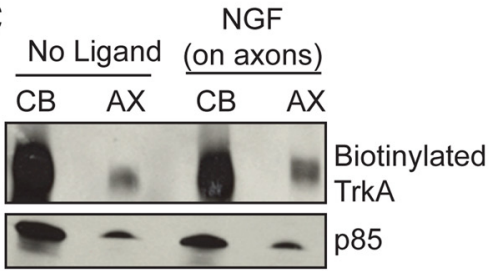

E

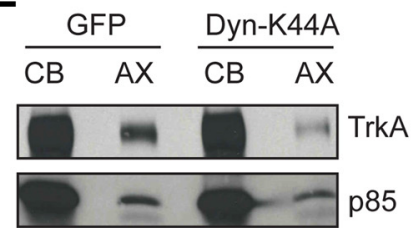

D

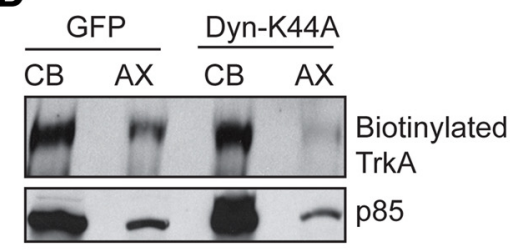

$\mathbf{F}$

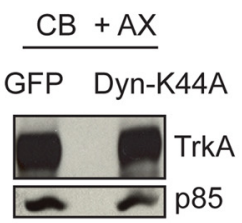

Figure 2. Trk receptors are transcytosed from neuronal soma surfaces to axons. $A$, Schematic of antibody feeding assay in compartmentalized cultures expressing FLAG-TrkB:A to follow transcytosis of Trk receptors originating from neuronal soma surfaces. $\boldsymbol{B}$, Representative images of cell bodies and axonal projections fixed and stained for anti-FLAG antibody. Anti-FLAGlabeled TrkB:A receptors are evident in cell bodies at $30 \mathrm{~min}$ and $4 \mathrm{~h}$ (small arrowheads) and in axons only in the $4 \mathrm{~h}$ incubations (large arrowheads). Scale bars, $5 \mu \mathrm{m}$. C, NGF treatment of axons $(100 \mathrm{ng} / \mathrm{ml}, 4 \mathrm{~h})$ enhances levels of biotinylated TrkA receptors in axons. Lysates from cell body (CB) and axon ( $\mathrm{AX}$ ) compartments in compartmentalized cultures were precipitated with neutravidin and immunoblotted with TrkA. Normalization for protein amounts was performed by immunoblotting for p85 subunit of PI3K. D, Dominant-negative dynamin (Dyn-K44A) inhibits TrkA transcytosis. Cell-surface biotinylation assay was performed in compartmentalized cultures expressing GFP or Dyn-K44A and treated with NGF on axons ( $100 \mathrm{ng} / \mathrm{ml}, 4 \mathrm{~h}) . \boldsymbol{E}, \boldsymbol{F}$, Dyn-K44A leads to a decrease in axonal, but not total, TrkA levels. Western blot analysis of TrkA levels in compartmentalized cultures $(\boldsymbol{E})$ shows that expression of Dyn-K44A leads to a significant decrease in axonal TrkA levels. Dyn-K44A does not affect total TrkA levels in neurons $(\boldsymbol{F})$.

\section{Rab11-positive recycling endosomes mediate TrkA transcytosis}

Cargo undergoing transcytosis in polarized epithelial cells are commonly transported to their final destinations via recycling endosomes (Altschuler et al., 2003; Tuma and Hubbard, 2003). FLAG antibody labeling of surface Trk receptors in neuronal cell bodies of compartmentalized cultures followed by immunostaining for the recycling endosome-associated small GTPase Rab11a (Zerial and McBride, 2001) showed that transcytosing Trk receptors colocalized or were in close apposition to Rab11immunoreactive vesicles (Fig. $3 A$ ) (50 \pm 6 and $45 \pm 5 \%$ of FLAG- immunopositive structures colocalized with endogenous Rab11 in cell bodies and axons, respectively). Transcytosing Trk receptors were also found to colocalize with Tf, a well established marker for the recycling pathway (Fig. $3 B$ ). Neurons expressing FLAG-TrkB:A receptors grown in compartmentalized cultures were loaded with anti-FLAG antibodies and Alexa546-Tf exclusively in cell body compartments. After $4 \mathrm{~h}$ of labeling, fixing and permeabilizing of neurons, and staining with a fluorescent secondary antibody for FLAG immunoreactivity, $47 \pm 4.5$ and $46 \pm 5 \%$ of FLAG-immunopositive structures colocalized with Alexa-546-Tf in cell bodies and axons, respectively. The degree of colocalization of FLAG-TrkB:A with Rab11 and transferrin was well above that observed with Rab4, a Rab GTPase implicated in a rapid recycling pathway (Maxfield and McGraw, 2004), and Rab7, a Rab protein associated with late endosomes and shown previously to be required for retrograde transport of neurotrophin receptors (Deinhardt et al., 2006) (supplemental Fig. 3, available at www.jneurosci.org as supplemental material).

To further investigate the role of Rab11 in TrkA trafficking, we also performed live imaging of sympathetic neurons expressing TrkA-GFP and mcherry-Rabll. A total of $62 \pm 6 \%$ of TrkA-GFP puncta were observed to be cotransported with Rab11positive structures in axons. Time-lapse imaging revealed punctae positive for both TrkA and Rab11 exhibiting highly dynamic bidirectional movements in axons, with an anterograde bias (Fig. 3C) (supplemental Movie 1, available at www. jneurosci.org as supplemental material). A representative kymograph shows punctae positive for both TrkA-GFP and mcherry-Rab11 exhibiting saltatory movement, switching from being stationary to rapid anterograde movement, followed by pausing (Fig. 3C). Kinetic analysis showed that, of the total number of double-positive carriers, $\sim 54 \%$ were stationary or pausing. Of the mobile ( $>0.6 \mu \mathrm{m} / \mathrm{s})$ double-positive carriers, $66 \%$ moved anterogradely, whereas $33 \%$ moved retrogradely, with an average speed of $1.2 \mu \mathrm{m} / \mathrm{s}$ in either direction (Fig. 3D). To specifically address the requirement of Rab11 in axonal transcytosis of Trk receptors, we assessed anterograde transport of Trk receptors originating from neuronal soma surfaces in neurons grown in compartmentalized cultures and infected with adenoviral vectors expressing GFP or a dominant-negative GDP-bound mutant form of Rab11a (Rab11aS25N) (Park et al., 2004). TrkA transcytosis was assessed by biotinylation of membrane proteins in cell body compartments and detection of transcytosed Trk receptors in axons by neutravidin precipitation and Western blotting. Indeed, expression of Rab1la- 
A

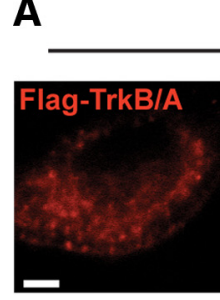

B

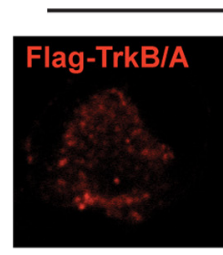

Cell Body

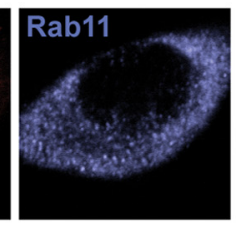

Cell Body
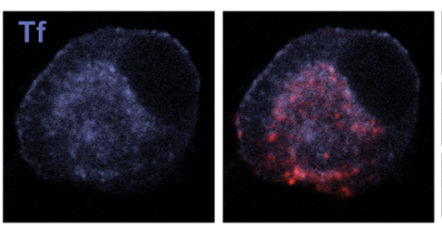

C

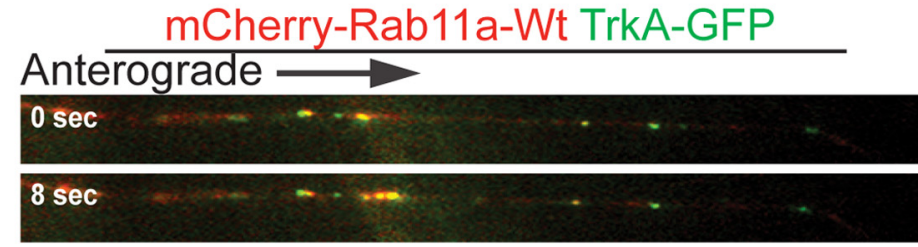

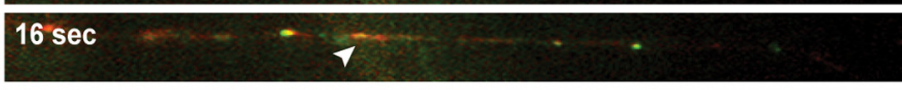

$24 \sec$

$32 \mathrm{sec}$

$40 \mathrm{sec}$

\section{$48 \mathrm{sec}$}

$56 \mathrm{sec}$

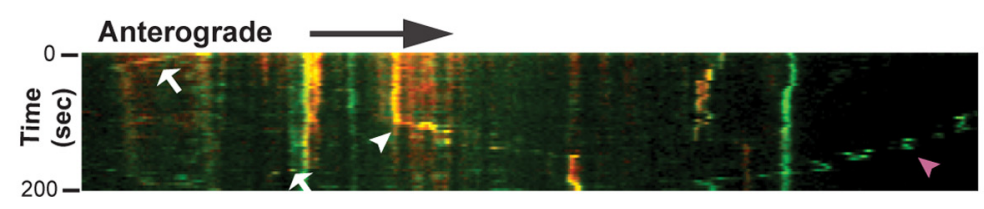

Axon

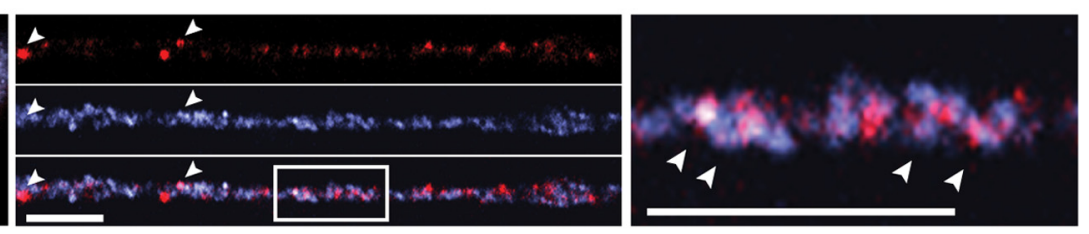

Axon
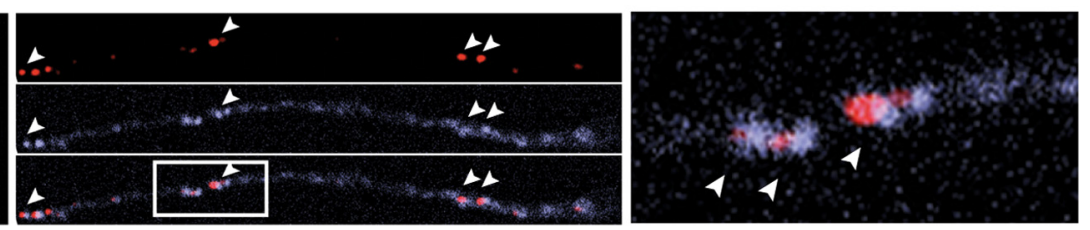

D

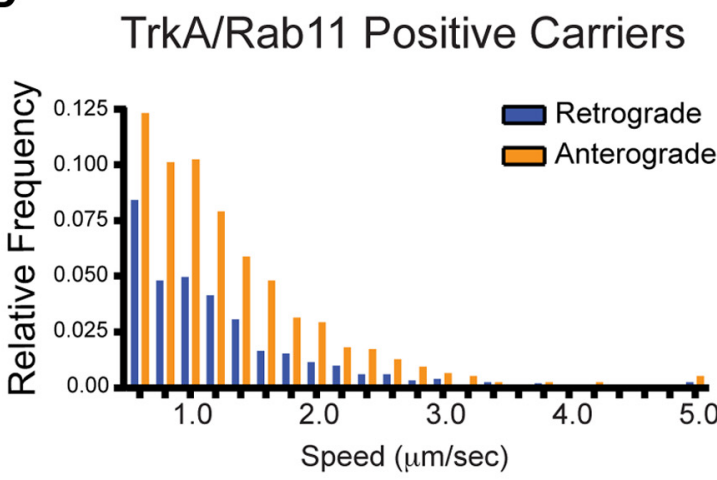

E

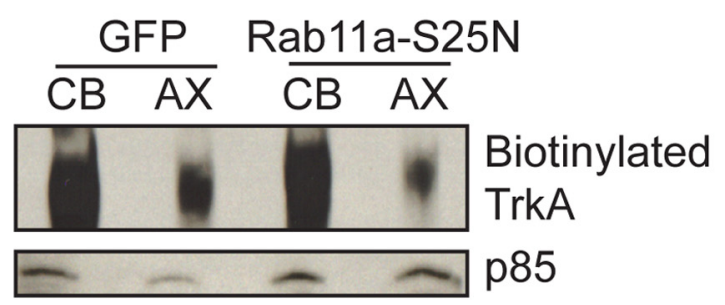

Figure 3. Rab11a mediates Trk transcytosis in sympathetic neurons. A, FLAG-TrkB:A receptors undergoing transcytosis colocalize with Rab11a in axons (arrowheads) as detected by immunostaining for FLAG antibody and endogenous Rab11a. Antibody-feeding assay was performed on compartmentalized cultures expressing FLAG-TrkB:A in the presence of BDNF ( $100 \mathrm{ng} / \mathrm{ml}, 4 \mathrm{~h})$ on axons. Boxed region in the middle is shown at higher magnification on the right. B, FLAG-TrkB:A receptors undergoing transcytosis colocalize with Alexa-546-labeled If (Alexa-546-Tf) in axons (arrowheads) as detected by immunostaining for FLAG antibody and Alexa-546 -Tf fluorescence. Cell body compartments of compartmentalized cultures expressing FLAG-TrkB:A were fed with FLAG antibodies and Alexa-546 -Tf under live conditions. After $4 \mathrm{~h}$ of labeling, neurons were fixed, permeabilized, and labeled with anti-mouse fluorescent secondary antibody to visualize FLAG-antibody-bound receptors. Boxed region in the middle is shown at higher magnification on the right. C, Individual frames from time-lapse microscopy of neurons expressing TrkA-GFP and mcherry-Rab11a, with corresponding kymograph (bottom). Anterogradely and retrogradely moving double-positive carriers are indicated by white arrowhead and white arrow, respectively, and purple arrowhead indicates a retrogradely moving structure positive for TrkA-GFP alone. Scale bars: $\boldsymbol{A}-\boldsymbol{C}, 5 \mu \mathrm{m} . \boldsymbol{D}$, Histogram showing speed distribution of mobile $(>0.6 \mu \mathrm{m} / \mathrm{s}$ ) carriers double positive for TrkA-GFP and mcherry-Rab11a. Quantification of 3289 single movements [defined as the distance traversed by a carrier between two consecutive frames (2s)] of 253 double-positive structures from a total of four independent experiments. E, Rab11a activity is required for TrkA transcytosis, as assessed by the biotinylation assay in compartmentalized cultures expressing GFP or Rab11a-S25N. AX, Axon; CB, cell body.

S25N caused a significant reduction (63 $\pm 0.09 \%$ decrease) in levels of biotinylated Trk receptors detected in axons, in the presence of NGF (Fig. $3 E)(p=0.02$, $t$ test; $n=3$ independent experiments). No significant differences in total levels of TrkA were detected between neurons expressing GFP and Rab11a-S25N, indicating that Rab11 functions in trafficking rather than expression of neuronal Trk receptors (supplemental Fig. 3, available at www.jneurosci.org as supplemental material). Together, these results provide evidence that Rab11-containing recycling endosomes mediate axonal transcytosis of Trk receptors.
NGF stimulation promotes rapid exocytosis of

TrkA receptors

We then asked whether neurotrophins, in addition to regulating Trk receptor mobilization to axons, also promote their insertion into the plasma membrane. Previous studies had suggested that TrkB receptors are rapidly recruited to the cell surface in response to neural activity or BDNF (Meyer-Franke et al., 1998; Du et al., 2000; Haapasalo et al., 2002). To determine whether NGF promotes TrkA exocytosis, sympathetic neurons were stimulated briefly ( 5 min pulse) with NGF, and surface levels of TrkA were 
A

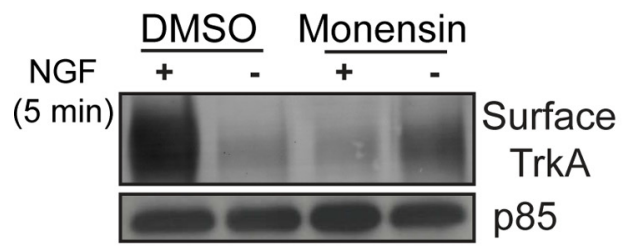

B

$\square$ DMSO $\square$ Monensin

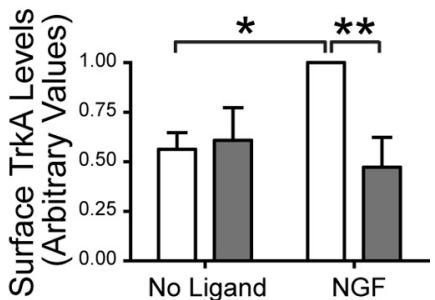

C TrkA-GFP (in Growth Cones)
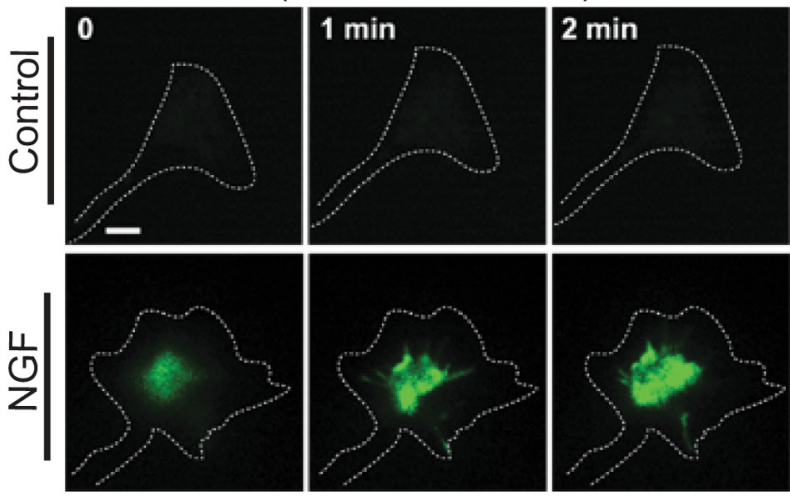

D

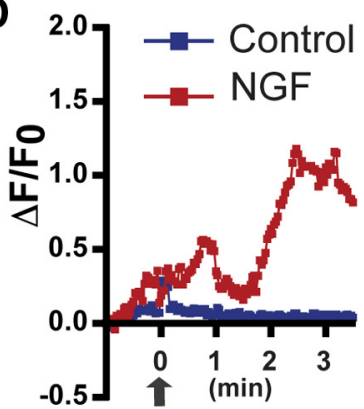

$\mathbf{F}$

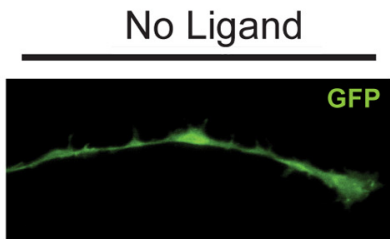

E
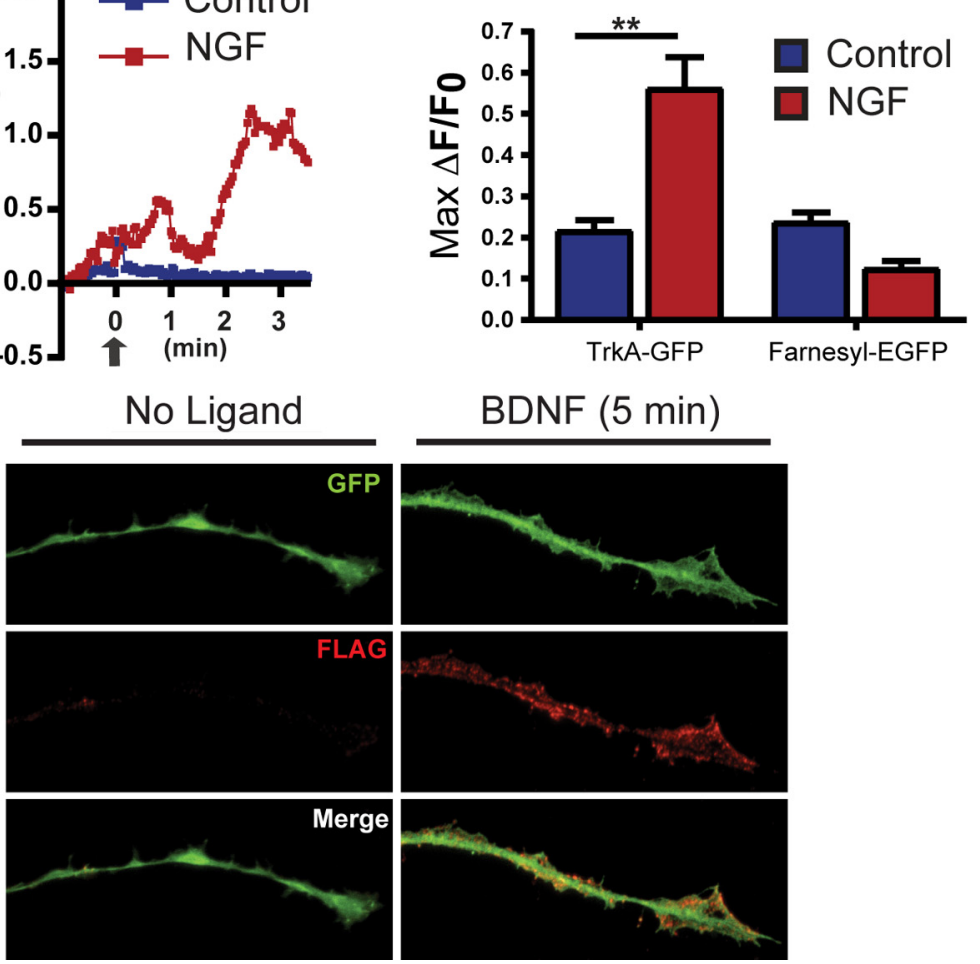

Figure 4. NGF stimulation promotes rapid exocytosis of TrkA from recycling endosomes. $\boldsymbol{A}$, TrkA is rapidly recruited to the cell surface during NGF stimulation. Levels of surface TrkA were assessed using cell-surface biotinylation in neuronal cultures briefly stimulated with a 5 min pulse of NGF $(100 \mathrm{ng} / \mathrm{ml})$ in the presence or absence of the recycling blocker monensin. Normalization for protein amounts was performed by immunoblotting neuronal lysates for $\mathrm{p} 85$ subunit of PI3K. $\boldsymbol{B}$, Densitometric quantification of the results shown in $\boldsymbol{A}$. Results are quantified relative to the NGF $(100 \mathrm{ng} / \mathrm{ml})$ condition, from eight independent experiments. ${ }^{*} p<0.05$ and ${ }^{* *} p<0.01$ as determined by one-way ANOVA, followed by a Dunnett's multiple comparison test. C, TIRF analyses of growth cones from neurons expressing TrkAGFP.Dashed lines outline the periphery of growth cones. Scale bar, $5 \mu \mathrm{m}$. D, Time course of TrkA-GFP fluorescence in the two growth cones depicted in $\boldsymbol{C}$. Arrow indicates time of NGF addition. $\boldsymbol{E}$, Group data showing maximum change in fluorescence (1-5 min) from growth cones of neurons expressing TrkA-GFP $(n=15)$ or farnesylated EGFP. Values are means \pm SEM from four independent experiments. ${ }^{* *} p=$ $0.003, t$ test. $\boldsymbol{F}$, Rapid BDNF-mediated surface delivery of FLAG-TrkB:A receptors originating from the plasma membrane. FLAG-TrkB:A receptors were live labeled with FLAG antibodies and allowed to internalize, surface antibodies were stripped off, and neurons were stimulated with BDNF for 5 min in the presence of a fluorescent secondary antibody. assessed by cell-surface biotinylation. We found that this short stimulus resulted in increased surface TrkA levels, which was attenuated in the presence of the recycling blocker monensin (Fig. 4A,B). Monensin treatment alone, in the absence of ligand, did not appreciably alter surface levels of TrkA within 5 min (Fig. 4B). TIRF analyses also revealed rapid recruitment to the surface of TrkA receptors during NGF stimulation in Cos-1 cells (supplemental Fig. 4, available at www.jneurosci.org as supplemental material) and axonal growth cones of neurons expressing TrkA-GFP (Fig. 4C) (supplemental Movie 2, available at www.jneurosci.org as supplemental material). NGF stimulation induced a significant increase in TrkA-GFP fluorescence at or near the surface (Fig. $4 C, D)$. NGF stimulation did not elicit any changes in surface fluorescence of a membrane-bound marker, farnesylated EGFP (Fig. 4E), suggesting that the observed increase in TrkA-GFP fluorescence is attributable to movement of vesicles relative to the plasma membrane and not attributable to generalized movement or expansion of the plasma membrane.

TrkA-GFP does not distinguish between newly synthesized receptors versus those that once resided on the plasma membrane. Additionally, our TIRF analysis showing increased fluorescence with neurotrophin stimulation at the axonal growth cones does not allow us to determine whether TrkA-GFP receptors are indeed being inserted into the plasma membrane as opposed to receptors merely approaching the plasma membrane. To investigate these two issues, we determined whether receptors being recruited to axonal growth cones with the very brief neurotrophin stimulation originate from a pool that once resided on the plasma membrane and whether they are indeed appearing on the axonal surface. Neurons expressing FLAG-TrkB:A receptors were live labeled with FLAG antibodies and stripped of surface antibodies after allowing internalization at $37^{\circ} \mathrm{C}$ in the absence of any ligand, and then axonal growth cones were stimulated with the ligand BDNF for $5 \mathrm{~min}$, in the presence of a fluorescent secondary antibody. BDNF treatment significantly increased FLAG immunofluorescence in axon terminals compared with unstimulated neurons (Fig. 4F). Because neurons were treated with the fluorescent secondary antibody under nonpermeabilizing conditions, these results are indicative of delivery to the axonal plasma membrane of recep- 
tors that had been previously on the cell surface during live labeling with FLAG antibodies. Given that constitutive internalization occurs predominantly in neuronal soma and is minimal in axons (Fig. $1 H$ ), we reason that the FLAG-antibody-bound receptors being recruited to axonal membranes originate primarily from soma surfaces. Together, these results suggest that Trk receptors held in intracellular endocytic compartments can indeed be rapidly mobilized to the cell surface during neurotrophin stimulation.

\section{Endocytic recycling modulates} neuronal sensitivity to NGF-dependent signaling and axon growth

To examine whether rapid mobilization of Trk receptors to neuronal surfaces via endocytic recycling imparts neuronal sensitivity to NGF, we assessed NGF-dependent signaling in neurons exposed to increasing concentrations of NGF for $5 \mathrm{~min}$, in the presence or absence of monensin. We found that, in neurons treated with monensin, higher concentrations of NGF were required to elicit similar levels of phosphorylation of TrkA and the downstream signaling effectors Akt and Erk1/2 seen in control neurons (Fig. $5 A, B$ ). The decrease in P-TrkA levels at high concentrations of NGF (1000 ng/ml) probably reflects rapid degradation of the receptor (Bogenmann et al., 1998), negative regulation of Trk activation by engagement of p75 receptors (MacPhee and Barker, 1997), or recruitment of a phosphatase (Marsh et al., 2003). Together, our results indicate that blockade of receptor recycling attenuates neuronal sensitivity to NGF.

To investigate the role of recycling in functional responses to target-derived NGF, we assessed the effects of a constitutively active GTP-bound variant of Rab11 (EGFPRab11a-Q70L) (Uhlig et al., 2006) and the dominant-negative EGFP-Rab11a-S25N mutant on axon growth in compartmentalized cultures when NGF is applied only to axons. Quantification of axon extension (micrometers per day) in response to axon-applied NGF revealed that enhancing recycling with Rab11a-Q70L conferred neuronal sensitivity to lower concentrations of NGF compared with control neurons expressing GFP (Fig. 5C,D). Conversely, neurons exhibit decreased responsiveness to NGF when recycling is impaired by expression of Rab11a-S25N (Fig. 5C,D). Increasing NGF concentration beyond saturating levels eliminated all differences in axon growth between cultures expressing the Rab11 variants and control cultures (Fig. 5D). Because the inhibitory effects of EGFP-Rab1la-S25N on axon
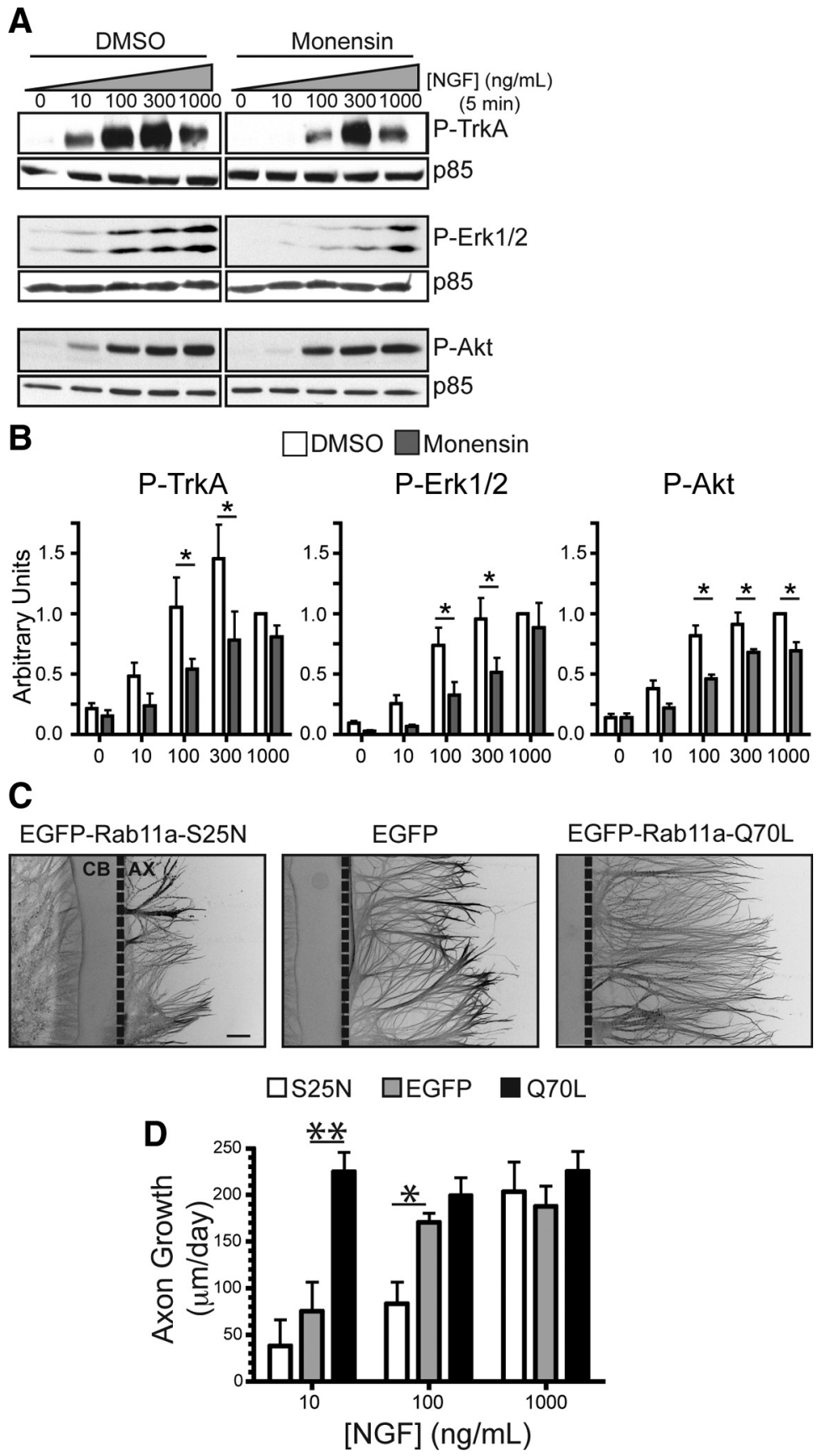

Figure 5. NGF-induced TrkA exocytosis modulates neuronal sensitivity to NGF-dependent signaling and axon growth. $\boldsymbol{A}$, Blocking endocytic recycling attenuates NGF-dependent signaling. Neuronal cultures were briefly stimulated ( $5 \mathrm{~min}$ ) with indicated concentrations of NGF in the presence or absence of the recycling blocker monensin $(10 \mu \mathrm{m})$. Lysates were immunoblotted to detect P-TrkA, P-Erk1/2, and P-Akt. Normalization for protein amounts was performed by stripping the immunoblots and reprobing for p85. $\boldsymbol{B}$, Densitometric quantification of the results shown in $\boldsymbol{A}$. Results are quantified relative to the NGF $(1000 \mathrm{ng} / \mathrm{ml})$ condition, from seven independent experiments. ${ }^{*} p<0.05$ as determined by two-way ANOVA, followed by Bonferroni's post hoc test. $C, D$, Rab11a activity regulates NGF-dependent axon growth. Compartmentalized cultures were infected with adenoviruses expressing GFP or Rab11 constructs, EGFP-Rab11a-S25N (dominant-negative) and EGFP-Rab11a-Q70L (constitutively active), and maintained with NGF added solely to the axonal compartments. Rate of axon extension (micrometers per day) was assessed for $72 \mathrm{~h}$. Panels in C are representative images of axons immunostained with anti- $\beta$-III tubulin. Separation between cell body (CB) and axon (AX) compartments is indicated by dashed line. $D$, Graph shows quantification of axon growth. Values are means \pm SEM from seven independent experiments. ${ }^{*} p<0.05$ and ${ }^{* *} p<0.01$, two-way ANOVA analysis with Bonferroni's post hoc test.

growth can be overcome by increasing NGF concentrations, these results suggest that blocking Rab11 function delays neuronal responsiveness to NGF rather than having a global effect on neuronal viability. Together, these results imply that Rab11-dependent recy- 


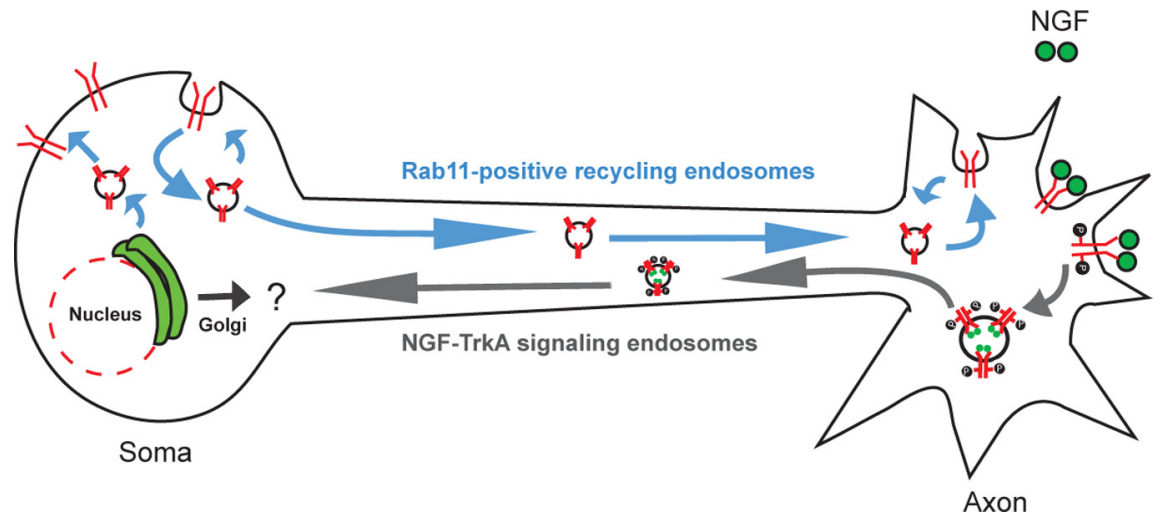

Figure 6. Model for TrkA transcytosis in sympathetic neurons. Newly synthesized TrkA receptors are first inserted into the neuronal soma surfaces, where they undergo constitutive endocytosis and subsequent axonal targeting via Rab11-positive recycling endosomes (blue arrows). In the absence of ligand, more receptors are internalized in neuronal soma compared with axons, promoting a net flow toward axons. NGF signaling initiated at axon terminals triggers a transient increase in surface TrkA levels through local exocytosis from intracellular receptor pools, followed by endocytosis and retrograde transport of activated receptors in nerve terminals (gray arrows). Retrograde NGF signaling enhances transcytosis leading to the anterograde delivery of additional TrkA receptors. The contribution of the secretory pathway to axonal targeting of Trk receptors remains to be determined.

cling facilitates sensitive neuronal responses to the limiting concentrations of target-derived NGF found in vivo.

\section{Discussion}

By using compartmentalized cultures in this study, we investigated axonal targeting of Trk receptors in response to targetderived neurotrophins in developing sympathetic neurons. Trk receptors are constitutively endocytosed preferentially in cell bodies, thereby generating a dynamic reservoir of intracellular receptors that can then be delivered to axons via Rab11containing recycling endosomes. We show that ligand acting locally in axons can recruit receptors from neuronal soma surfaces by regulating this transcytotic trafficking pathway. Perturbing endocytic recycling attenuated NGF-dependent signaling and functional responses, whereas enhancing recycling increased neuronal responsiveness to NGF. Our findings suggest that regulated anterograde trafficking of Trk receptors is a mechanism to amplify neuronal responsiveness to the limiting amounts of target-derived neurotrophins found in vivo.

Currently, the trafficking mechanisms by which signaling receptors are targeted to axons are poorly understood, despite the implications for how neurons might respond to extracellular cues promoting migration, axon growth, guidance, and neuronal survival. Previous studies have shown that, like the targeting of apical membrane proteins in polarized epithelial cells via transcytosis, neurons use endocytic mechanisms for targeting of some axonal proteins. A well characterized example is L1/NgCAM, a cell adhesion molecule important for axon guidance; initial delivery of $\mathrm{L} 1 / \mathrm{NgCAM}$ to the somatodendritic compartment in hippocampal neurons is followed by endocytosis and transport to axonal surfaces via recycling endosomes (Wisco et al., 2003; Winckler, 2004; Anderson et al., 2005; Yap et al., 2008a,b). However, the physiological relevance of such a trafficking pathway in developing neurons and its regulation by extracellular signals still remains elusive.

Based on our findings, we propose that transcytosis might be a more general mechanism than currently appreciated for axonal delivery of receptors in response to extracellular signals impinging locally on axonal growth cones. Thus, target-derived neurotrophins, acting on terminals of axons that can be millimeters long, recruit their own receptors to their sites of action through transcytosis, and this process influences developmental outcomes such as axon growth. Transcytotic trafficking provides the advantage of using ready-synthesized receptors to axons. Membrane trafficking through the endocytic pathway has been reported to be 10 times greater than through the secretory pathway (Horton and Ehlers, 2003), suggesting that the former might provide a larger intracellular reservoir of membrane proteins for regulated delivery to the cell surface. The considerable heterogeneity of endocytic organelles compared with Golgi-derived vesicles might also allow for more plasticity in the regulation of axonal trafficking. We found that Rab11, a small Rab GTPase predominantly found in recycling endosomes, regulates anterograde Trk transcytosis and NGF-dependent axonal extension. Interestingly, protrudin, a Rab11-binding protein, has been implicated in directional membrane trafficking leading to NGF-mediated neurite outgrowth in PC12 cells (Shirane and Nakayama, 2006). However, unlike our results, protrudin requires GDP-bound Rab11 to mediate neurite outgrowth, although we find that axon extension is inhibited by the GDP-bound mutant form of Rab11a (Rab11a-S25N) and enhanced by the GTP-bound Rab11a-Q70L. These results may present an interesting difference between mechanisms that initiate neurite outgrowth from those involved in axonal extension. Although our data indicates that Rab11-positive recycling endosomes mediate axonal transport of Trk receptors, it is likely that receptors internalizing from neuronal soma surfaces have to traverse through several intermediate compartments, including early endosomes and/or multivesicular bodies, before entering axons, as seen for L1/NgCAM (Yap et al., 2008b).

In previous studies of axonal targeting of $\mathrm{NgCAM}$, a point of contention has been whether the protein indeed resides transiently on somatodendritic surfaces, before axonal delivery (Horton and Ehlers, 2003; Sampo et al., 2003; Wisco et al., 2003). By performing cell-surface biotinylation and antibody-feeding assays in compartmentalized cultures, we have provided direct evidence that Trk receptors residing on neuronal soma surfaces are indeed transported anterogradely to axons. These results imply that newly synthesized Trk receptors are first inserted into the plasma membrane of neuronal cell bodies, before being retrieved by endocytosis and anterogradely transported. Insertion of Trk receptors into the plasma membrane of cell bodies before the long journey down the axons might be required to "unmask" an axonal targeting signal, perhaps, via posttranslational modifications or proteolytic processing. In this regard, NgCAM with a point mutation in a tyrosine-based YRSLE motif was found to avoid the transcytotic route and was shipped directly to axons (Wisco et al., 2003), pointing to a role for phosphorylation in regulating transcytosis. It is also tempting to speculate that internalization of unliganded TrkA receptors in neuronal cell bodies acts as a quality control step for the axonal targeting of an "endocytosis-competent" pool of receptors that can then be quickly internalized in response to NGF at the axon terminals.

Although retrograde transport of TrkA receptors to mediate NGF-dependent trophic responses has been extensively studied, other modes of Trk trafficking in neurons are poorly understood. 
Previous studies examining TrkA recycling have yielded differing results; Chen et al. (2005) showed significant ligand-dependent recycling of TrkA receptors, whereas Saxena et al. (2005) reported very little TrkA recycling when compared with p 75 neurotrophin receptors that recycle robustly in response to NGF (Bronfman et al., 2003; Saxena et al., 2005). These studies performed in nonpolarized PC12 cells may not completely recapitulate spatial aspects of receptor trafficking in morphologically complex neurons. We show in sympathetic neurons that Trk receptors undergo ligandindependent internalization primarily in cell bodies, although recycling of internalized receptors is equivalent in cell bodies and axons. Similar to our observations with Trk receptors in sympathetic neurons, p75 receptors recycle in a ligandindependent manner in both cell bodies and axons of motor neurons (Deinhardt et al., 2007), although it remains to be determined whether these receptors are also targeted to axon terminals via regulated transcytosis, as we observed for TrkA. It must be noted here that, although our study highlights a role for long-distance anterograde recycling of unliganded Trk receptors in amplifying neurotrophin responses, local recycling of ligandbound receptors in axonal growth cones might also contribute to NGF-dependent functional responses, specifically, local events such as growth cone motility, morphological responses, and guidance. Using a cell-surface biotinylation assay, we did not observe any significant effects of the recycling blocker monensin on levels of TrkA internalized in response to NGF in mass cultures of sympathetic neurons, similar to the results obtained in PC12 cells (Saxena et al., 2005). However, this does not argue against NGF-dependent recycling of internalized TrkA receptors, especially if it occurs in distinct subcellular locations such as axonal processes, which would not have been detected in our assay.

We also observed that NGF treatment results in rapid exocytosis of TrkA receptors to sympathetic growth cones, similar to previous observations for BDNF-induced recruitment of TrkB receptors in hippocampal neurons. BDNF rapidly increased surface TrkB levels within seconds, whereas ligand-induced endocytosis of receptors occurred on a timescale of minutes (Haapasalo et al., 2002). More quantitative kinetic analyses combined with live imaging will be required to temporally separate the two events occurring locally at the sympathetic growth cones. However, it seems reasonable to propose that, like BDNF, NGF rapidly recruits TrkA receptors from a local intracellular pool within axon terminals, followed by endocytosis of active receptors. Because exocytosis of TrkB receptors has been demonstrated to be regulated by activity and intracellular second messengers such as $\mathrm{Ca}^{2+}$ and cAMP (Meyer-Franke et al., 1998; Du et al., 2000), it will also be important to define whether similar mechanisms underlie the transcytosis and local exocytosis of TrkA receptors.

Target-derived NGF initiates a positive feedback loop by inducing expression of TrkA receptors to enhance the magnitude and duration of prosurvival signaling during neuronal competition for survival (Deppmann et al., 2008). Our results suggest an additional positive feedback mechanism in which limiting concentrations of target-derived neurotrophins rapidly recruit their receptors to axons via transcytosis and promote their exocytosis into growth cones, to amplify neuronal responsiveness and gain a competitive advantage. In this trafficking-based feedback model, the first axons to reach NGF-expressing targets would not only gain access to limiting levels of NGF but also propagate a retrograde signal to neuronal cell bodies to anterogradely transport more receptors to nerve terminals via transcytosis. To integrate our observations, we propose a model in which an initial response of axons to NGF triggers a transient increase in surface
TrkA levels through local exocytosis from intracellular receptor pools, followed by endocytosis and retrograde transport of activated receptors in nerve terminals. Subsequently, retrograde NGF signaling enhances anterograde delivery of additional TrkA receptors by drawing on a larger intracellular pool residing in cell bodies (Fig. 6). In future studies, it will be important to define the nature of the retrograde signal that regulates anterograde Trk trafficking, whether it is signaling-endosome-based or mediated by long-range calcium signaling from growth cones to neuronal soma as reported recently for Slit-dependent migration of cerebellar granule cells (Guan et al., 2007), and how this signal is propagated to mature Trk receptors residing on neuronal soma surfaces.

In a broader context, anterograde transcytosis and membrane trafficking from recycling endosomes might also be of relevance to axons navigating through gradients of guidance cues. Axons, during pathfinding, undergo a process of adaptation by consecutive cycles of endocytosis-dependent desensitization and local protein synthesis-mediated resensitization (Ming et al., 2002; Piper et al., 2005). This adaptational mechanism is believed to reset the sensitivity of growth cones to guidance cues as they move up a gradient of an extracellular ligand. Our results show that blockade of Trk receptor recycling attenuates neuronal sensitivity to NGF. Thus, membrane trafficking from recycling endosomes might work in parallel with local protein synthesis, to rapidly mobilize trophic and guidance receptors to axon growth cones, thus allowing them to dynamically interpret gradients of developmental cues.

\section{References}

Altschuler Y, Hodson C, Milgram SL (2003) The apical compartment: trafficking pathways, regulators and scaffolding proteins. Curr Opin Cell Biol 15:423-429.

Anderson E, Maday S, Sfakianos J, Hull M, Winckler B, Sheff D, Fölsch H, Mellman I (2005) Transcytosis of NgCAM in epithelial cells reflects differential signal recognition on the endocytic and secretory pathways. J Cell Biol 170:595-605.

Atwal JK, Massie B, Miller FD, Kaplan DR (2000) The TrkB-Shc site signals neuronal survival and local axon growth via MEK and P13-kinase. Neuron 27:265-277.

Bastaki M, Braiterman LT, Johns DC, Chen YH, Hubbard AL (2002) Absence of direct delivery for single transmembrane apical proteins or their "secretory" forms in polarized hepatic cells. Mol Biol Cell 13:225-237.

Basu SK, Goldstein JL, Anderson RG, Brown MS (1981) Monensin interrupts the recycling of low density lipoprotein receptors in human fibroblasts. Cell 24:493-502.

Bezzerides VJ, Ramsey IS, Kotecha S, Greka A, Clapham DE (2004) Rapid vesicular translocation and insertion of TRP channels. Nat Cell Biol 6:709-720.

Bogenmann E, Peterson S, Maekawa K, Matsushima H (1998) Regulation of NGF responsiveness in human neuroblastoma. Oncogene 17:2367-2376.

Bronfman FC, Tcherpakov M, Jovin TM, Fainzilber M (2003) Ligandinduced internalization of the p75 neurotrophin receptor: a slow route to the signaling endosome. J Neurosci 23:3209-3220.

Chen ZY, Ieraci A, Tanowitz M, Lee FS (2005) A novel endocytic recycling signal distinguishes biological responses of Trk neurotrophin receptors. Mol Biol Cell 16:5761-5772.

Deinhardt K, Salinas S, Verastegui C, Watson R, Worth D, Hanrahan S, Bucci C, Schiavo G (2006) Rab5 and Rab7 control endocytic sorting along the axonal retrograde transport pathway. Neuron 52:293-305.

Deinhardt K, Reversi A, Berninghausen O, Hopkins CR, Schiavo G (2007) Neurotrophins redirect p75NTR from a clathrin-independent to a clathrin-dependent endocytic pathway coupled to axonal transport. Traffic 8:1736-1749.

Delcroix JD, Valletta JS, Wu C, Hunt SJ, Kowal AS, Mobley WC (2003) NGF signaling in sensory neurons: evidence that early endosomes carry NGF retrograde signals. Neuron 39:69-84.

Deppmann CD, Mihalas S, Sharma N, Lonze BE, Niebur E, Ginty DD (2008) 
A model for neuronal competition during development. Science 320:369-373.

Du J, Feng L, Yang F, Lu B (2000) Activity- and $\mathrm{Ca}^{2+}$-dependent modulation of surface expression of brain-derived neurotrophic factor receptors in hippocampal neurons. J Cell Biol 150:1423-1434.

Grimes ML, Zhou J, Beattie EC, Yuen EC, Hall DE, Valletta JS, Topp KS, LaVail JH, Bunnett NW, Mobley WC (1996) Endocytosis of activated TrkA: evidence that nerve growth factor induces formation of signaling endosomes. J Neurosci 16:7950-7964.

Guan CB, Xu HT, Jin M, Yuan XB, Poo MM (2007) Long-range $\mathrm{Ca}^{2+}$ signaling from growth cone to soma mediates reversal of neuronal migration induced by slit-2. Cell 129:385-395.

Haapasalo A, Sipola I, Larsson K, Akerman KE, Stoilov P, Stamm S, Wong G, Castren E (2002) Regulation of TRKB surface expression by brainderived neurotrophic factor and truncated TRKB isoforms. J Biol Chem 277:43160-43167.

Heerssen HM, Pazyra MF, Segal RA (2004) Dynein motors transport activated Trks to promote survival of target-dependent neurons. Nat Neurosci 7:596-604.

Hémar A, Olivo JC, Williamson E, Saffrich R, Dotti CG (1997) Dendroaxonal transcytosis of transferrin in cultured hippocampal and sympathetic neurons. J Neurosci 17:9026-9034.

Horton AC, Ehlers MD (2003) Neuronal polarity and trafficking. Neuron 40:277-295.

Jullien J, Guili V, Derrington EA, Darlix JL, Reichardt LF, Rudkin BB (2003) Trafficking of TrkA-green fluorescent protein chimerae during nerve growth factor-induced differentiation. J Biol Chem 278:8706-8716.

Kuruvilla R, Ye H, Ginty DD (2000) Spatially and functionally distinct roles of the PI3-K effector pathway during NGF signaling in sympathetic neurons. Neuron 27:499-512.

Kuruvilla R, Zweifel LS, Glebova NO, Lonze BE, Valdez G, Ye H, Ginty DD (2004) A neurotrophin signaling cascade coordinates sympathetic neuron development through differential control of TrkA trafficking and retrograde signaling. Cell 118:243-255.

Leterrier C, Lainé J, Darmon M, Boudin H, Rossier J, Lenkei Z (2006) Constitutive activation drives compartment-selective endocytosis and axonal targeting of type 1 cannabinoid receptors. J Neurosci 26:3141-3153.

MacPhee IJ, Barker PA (1997) Brain-derived neurotrophic factor binding to the p75 neurotrophin receptor reduces TrkA signaling while increasing serine phosphorylation in the TrkA intracellular domain. J Biol Chem 272:23547-23551.

Marsh HN, Dubreuil CI, Quevedo C, Lee A, Majdan M, Walsh GS, Hausdorff S, Said FA, Zoueva O, Kozlowski M, Siminovitch K, Neel BG, Miller FD, Kaplan DR (2003) SHP-1 negatively regulates neuronal survival by functioning as a TrkA phosphatase. J Cell Biol 163:999-1010.

Maxfield FR, McGraw TE (2004) Endocytic recycling. Nat Rev Mol Cell Biol 5:121-132.
Meyer-Franke A, Wilkinson GA, Kruttgen A, Hu M, Munro E, Hanson MG Jr, Reichardt LF, Barres BA (1998) Depolarization and cAMP elevation rapidly recruit TrkB to the plasma membrane of CNS neurons. Neuron 21:681-693.

Ming GL, Wong ST, Henley J, Yuan XB, Song HJ, Spitzer NC, Poo MM (2002) Adaptation in the chemotactic guidance of nerve growth cones. Nature 417:411-418.

Mobley WC, Schenker A, Shooter EM (1976) Characterization and isolation of proteolytically modified nerve growth factor. Biochemistry 15:5543-5552.

Park M, Penick EC, Edwards JG, Kauer JA, Ehlers MD (2004) Recycling endosomes supply AMPA receptors for LTP. Science 305:1972-1975.

Piper M, Salih S, Weinl C, Holt CE, Harris WA (2005) Endocytosisdependent desensitization and protein synthesis-dependent resensitization in retinal growth cone adaptation. Nat Neurosci 8:179-186.

Sampo B, Kaech S, Kunz S, Banker G (2003) Two distinct mechanisms target membrane proteins to the axonal surface. Neuron 37:611-624.

Saxena S, Howe CL, Cosgaya JM, Steiner P, Hirling H, Chan JR, Weis J, Krüttgen A (2005) Differential endocytic sorting of p75NTR and TrkA in response to NGF: a role for late endosomes in TrkA trafficking. Mol Cell Neurosci 28:571-587.

Shirane M, Nakayama KI (2006) Protrudin induces neurite formation by directional membrane trafficking. Science 314:818-821.

Tuma PL, Hubbard AL (2003) Transcytosis: crossing cellular barriers. Physiol Rev 83:871-932.

Uhlig M, Passlack W, Eckel J (2006) Identification and characterization of a novel variant in the highly conserved catalytic center of Rab1 la. Eur J Med Genet 49:29-36.

Winckler B (2004) Scientiae forum/models and speculations pathways for axonal targeting of membrane proteins. Biol Cell 96:669-674.

Wisco D, Anderson ED, Chang MC, Norden C, Boiko T, Fölsch H, Winckler B (2003) Uncovering multiple axonal targeting pathways in hippocampal neurons. J Cell Biol 162:1317-1328.

Yap CC, Nokes RL, Wisco D, Anderson E, Fölsch H, Winckler B (2008a) Pathway selection to the axon depends on multiple targeting signals in NgCAM. J Cell Sci 121:1514-1525.

Yap CC, Wisco D, Kujala P, Lasiecka ZM, Cannon JT, Chang MC, Hirling H, Klumperman J, Winckler B (2008b) The somatodendritic endosomal regulator NEEP21 facilitates axonal targeting of L1/NgCAM. J Cell Biol 180:827-842.

Ye H, Kuruvilla R, Zweifel LS, Ginty DD (2003) Evidence in support of signaling endosome-based retrograde survival of sympathetic neurons. Neuron 39:57-68.

Zerial M, McBride H (2001) Rab proteins as membrane organizers. Nat Rev Mol Cell Biol 2:107-117.

Zweifel LS, Kuruvilla R, Ginty DD (2005) Functions and mechanisms of retrograde neurotrophin signalling. Nat Rev Neurosci 6:615-625. 